\title{
THE RELATIONS OF COMPLEX AND SENTIMENT. IV.1
}

\author{
BY T. H. PEAR.
}

ONE of the chief features of this discussion is to be a concerted attempt to attach workable meanings to the words 'complex' and 'sentiment.' The historical origin of the term 'complex' has now been clearly traced, leaving us free to open up other paths. Of those paths the one which tempts me most is that which will lead to an inquiry into the reasons why the meaning of the word 'complex' has 'worked loose'-to borrow Dr F. C. S. Schiller's expressive phrase-so soon. To discuss the factors responsible for this dislocation may help us better to judge whether those meanings which offer themselves as possible supplanters of the original are likely to prove themselves inferior or superior to it.

The object of this paper is to examine some of the meaningswhether they are yet correctly labelled or not-which have come into being as a result of the original expositions by Drs Neisser and Jung of certain conceptions which they had found useful, and of the popularization of these expositions by Dr Bernard Hart and others. I believe that the impetus given to the general study of the subject by these writers has accelerated the crystallization of yet another concept, which may either be termed a complex, or, if that name be denied it, is almost certain to demand one of its own.

I will now endeavour to describe the main features of this concept. Let us begin by accepting provisionally the definition of a sentiment as an organized system of emotional dispositions grouped about an object. This description is so closely packed with meaning that to lay out its contents within the confined space of this article is not an easy task. We will first examine that aspect of it, which in the opinion of some psychologists does violence to the accepted usage of speech; its implication that a sentiment, being a system of emotional dispositions, is never actually experienced, but is part of the structure of the mind. It is true that everyday speech commonly attributes to a sentiment the capacity of being experienced, but our language has probably employed the word

1 A contribution to the Symposium prepared for the Meeting of the British Psychological Society in Manchester, July, 1922. 
in so many ways that more than one meaning might be found by an appeal to it. And my personal experience has not been that the average educated man's sensibilities are very much shocked by this proposal to employ the word 'sentiment' for the enduring organization of mind and body through the action of which he experiences emotions of various qualities and intensities, in relation to an object. Not a few welcome the suggestion that when they love ${ }^{1}$ a person, what they actually experience at any moment, when the perception or the idea of the loved one excites in them an affective disturbance, is a blend of emotions, referring to the object; while the fact that they can be said to love someone who is absent not only from their physical environment but from their temporary consciousness, is explicable by the supposition that the person has caused an enduring change in the functional pattern of their mind, and correspondingly, of their nervous system. Love seems to be a force too mighty to be identified with temporary emotions.

This conception, I take it, is that of Prof. McDougall. Though I am at present uncertain whether the view which will now be outlined is compatible with Mr Shand's own view of the sentiment, I think this to be possible.

Let us now attempt to distinguish sentiment from complex along the lines of the above definition. Both are alike in that they are made up of emotional tendencies. The important aspect in which they appear to differ is this; that while the sentiment is an organized system of emotional tendencies grouped about the object, the complex-in the sense of the word which will now be expounded-seems to be a relatively unorganized collocation, sometimes almost a fortuitous concourse, of such tendencies collected about an object.

This difference between sentiment and complex may be discussed from two points of view. We may examine the way in which the internal structure of these two systems differs, or the different kinds of behaviour which they prompt. Let us attempt the first of these tasks.

While the internal arrangement of the emotional dispositions in the sentiment appears to be orderly, those in the complex seem in comparison to be untidily thrown together. One presents the trimness of a Dutch garden; the other exhibits the tangle and the undergrowth of the jungle. It will perhaps be remarked that some apparently tidy gardens contain a corner with undergrowth, usually a little difficult to discover by a casual glance. Moreover, some so-called complexes are very nearly

1 For obvious reasons this is the sentiment which is naturally chosen as an example when this question is debated. 
sentiments, but for various reasons are not called by that name; sometimes because it would be unpleasant to recognize them as such, sometimes because society has not acknowledged them or has not yet invented their names. One reason why the sentiments, like the gardens, of a wellbred and fortunate person are apt to be tidy is that they have long been carefully tended by those influential gardeners, his teachers and parents. And it is noteworthy that the two concepts of sentiment and complex, as used in modern psychology, grew up as a result of considering the tidy and the untidy aspects of mind respectively.

Let us now illustrate this distinction; incidentally putting it to the test by considering certain examples of behaviour, all of which lie in that vast No Man's Land between orderly and disorderly mentality and defy the psychologist to call them either normal or morbid.

(1) I know a man who in his undergraduate days was devotedly attached to a political party which was working for a certain end, at that time unpopular. He gladly and proudly faced opposition and ridicule, speaking repeatedly in favour of the reform, and was encouraged in person by the leaders of the movement. He went to live in another country where he spread the gospel as energetically as before. One day these leaders, by now famous, came to speak in the town where he was living, and he hastened to greet them after the meeting. Either through weariness or lack of interest they spoke to him perfunctorily and soon bowed themselves away. From that day forward he began to master the writings of persons antagonistic to the proposed reform. In a few years' time he had not only amassed a considerable knowledge of the objections to the reform-but almost imperceptibly, this activity in research had replaced his original propagandist work. All this time, however, he believed himself to be a whole-hearted supporter of the 'cause.' A book on 'complexes' caused him to trace back in his memory the details of this part of his life. He then discovered that his whole change of attitude, his comparative lack of active support, with his theoretical interest in the opponent side, dated back to the hour of his rebuff.

The interpretation of this series of events seems to be that he had not formed a sturdy, 'tidy' sentiment of hatred towards those who had snubbed him, nor that his sentiment for scientific truth had instantaneously spread to this special political subject, but that in place of the original sentiment of affection which was shattered by the rebuff there remained ruins, interpenetrated by new growths; the whole forming an untidy collocation. The result of this upon behaviour was that his conduct 
towards the leaders, comparatively predictable if a sentiment of love or hate were in question, would, while the complex dominated it, be unpredictable. And it is this predictability of behaviour which is one outstanding feature-though not, I believe, an invariably distinctive one - of the sentiment.

The reader will not unnaturally inquire by whom the conduct arising from the sentiment and the complex are predictable and unpredictable respectively. The answer may be given in these words. The conduct of a person possessing a well-developed sentiment or an integration of such sentiments can be predicted by another person who himself either possesses similar sentiments or is the owner of insight and sympathy sufficient to enable him to apprehend the quality of a sentiment which he himself does not possess or possesses only in a small degree. The complex, on the other hand, leads to unpredictable behaviour because of the relative lack of organization and grouping of its emotional tendencies around the object. To the objection that any particular person may judge another's behaviour towards a certain object to be disorderly or unpredictable because he has not appreciated the nature of a sentiment prompting it, I would reply that this is an incidental difficulty of practice well known to the ethnologist and to the psycho-therapist. It points to the necessity of possessing wide sympathies and knowledge if one is to succeed in the task of recognizing a sentiment when one meets it.

(2) Let us now consider the following situations. (a) A man is happily married, loves his wife and children and is loved by them. For years he has centred more and more of his pride and ambition upon his family. He now discovers that in order to give his children a good education it will be necessary for him to abandon an expensive hobby.

(b) A man is unmarried, rich, and has no relatives or friends whose affection or opinion he values highly. He possesses no very strong moral principles; he has neither religious faith nor sufficient knowledge to lead to agnostic convictions. Up to the present time his general behaviour has been free from serious blame. He falls in love with the wife of another man, and, though he has said nothing of this to her, he suspects that his love is returned.

Most of us, I believe, if circumstances brought us into relation with these two men, would have little hesitation in assuming that in case (a) the subsequent conduct is predictable, while in (b) it is unpredictable. Moreover, it is probable that if in case $(b)$ we find ourselves justified in predicting anything about the man's behaviour, it will be only as a 


\section{4}

The Relations of Complex and Sentiment

result of our discovery that he possesses strong sentiments for persons or objects connected with this particular situation; for example, the husband or the children.

(3) A single woman is charged before the court with neglecting her children. The magistrates must decide whether in future the children can be justifiably left in her charge. If the justices take their duties seriously they may have to consider whether she possesses any real sentiments for her children, and, if so, whether they are of love or hate, pride or shame, or if her mentality in these respects is so entangled that she cannot be said to have sentiments about them at all, but only complexes. Apart from economic considerations, the solution of this psychological problem is likely to be the chief determinant of their judgment.

I hope that the working value of this conception has now been demonstrated. Whether the collocation of emotional tendencies which we have thus distinguished from the sentiment should be given the name of complex or not, I do not know. But I think that several different conceptions of the complex are reconciled in this one. Yet, the believer in the essentially pathological nature of the complex may ask, is not this 'internal untidiness' the result of repression, and does not repression, therefore, serve admirably as the distinguishing mark of a complex?

I believe that the formation of a complex often necessitates considerable repression, in the wide sense of that word ${ }^{1}$, and that its effect is often to render a person's behaviour 'untidy' and unpredictable. But I believe also-and this prevents me from accepting repression as the differentia of a complex-that the development of some powerful and important sentiments, at least in society as we know it here and now, implies not a little repression; and moreover, that repression may increase the predictability or the unpredictability of the behaviour arising from a sentiment or a complex, according to circumstances ${ }^{2}$. Although particularly striking examples of complexes are often particularly striking examples of repression, I cannot yet agree that the presence or absence of repression can usefully be accepted as the criterion of a complex.

Alternatively, if the complex be defined in such a way, I think it will encourage psychologists, especially those who deal with the more pleasant and peaceful aspects of mind, to shut their eyes to the repression

1 This would include both Dr Rivers's conceptions of suppression and repression.

2 Upon the further question whether it can also, according to circumstances, increase the orderliness or disorderliness of organization of the emotional dispositions, I am not prepared to give an opinion. 
which often accompanies the formation of a sentiment; to repress, in fact, the thought of repression. Furthermore, there is a risk that ultimately the great value of certain words which now form part of the definition of a sentiment will be discounted. They are the words organized and grouped; perhaps even system. This recognition in current psychological theory of affective organization at a high level should be jealously guarded, for several reasons. One of these is known to every psychotherapist who successfully dissuades a patient from an unwise action by deliberately, and with psychological insight, playing upon his sentiments, and who sometimes fails because around the persons or objects in question the sick man has woven not sentiments but complexes. The other reason is that, at a period of history when the mental differences between man and the lower animals are more difficult to demonstrate than formerly, psychology should lose no chance of bearing witness to one development in which man undoubtedly seems to be superior to them.

It is clear that the concept of repression had nearly formulated itself before Freud's time. It was present in psychology, though unnamed, when William James wrote, with that unmistakable stamp of firsthandedness, of "some mental objects which for the time being will not develop. They simply go out": it reappears repeatedly in his Principles and can be found in the Varieties of Religious Experience. It is implicit in most modern expositions of attention, memory and thought, and in the physiologist's accounts of inhibition and of reciprocal innervation of antagonistic muscles. Recently, throughout his book, Instinct and the Unconscious, Dr Rivers has laid stress not only upon its naturalness but upon its necessity. It would not be surprising, therefore, if it entered into the manufacture of the sentiments; and I believe that it not infrequently does $\mathbf{1}$.

Let us consider two widespread and important sentiments, love for someone of the other sex, and patriotism. Most civilized persons can appreciate the fact that a particular man should love his wife or his country while, maybe, finding it difficult to understand how it is that the man can love that particular woman or that particular country. Relatively simple, uneducated and aesthetically uncultured minds may form such sentiments without any repression; but can we seriously believe this to be true of a keenly intelligent and cultivated mind? Must not the lover, whether of his country or of his mistress, find some things in her which, in any other land or person, he would wish to be altered,

\footnotetext{
I In his contribution to this symposium, Dr Rivers writes that suppression may take "a secondary part in the production of the sentiment."
} 
and does not love descend gently upon these defects, clouding their stark angularity?

\author{
"Be to her faults a little blind \\ Be to her virtues very kind"
}

and, though written in a different key:

"My country, right or wrong,"

do not they describe repression, and is not the behaviour to which they lead all the more predictable because of its action? Again, is it not true of the psychasthenic person that his mind is unusually incapable of forming and of utilizing 'logic-tight compartments'; exceptionally poorly equipped with resistive mental armour which makes life simpler for the un-finicky strong man of action? Probably the 'efficient action upon reality' which occupies the highest level in Janet's hierarchy of actions involves not a little repression if the constitution either of the reality or the agent is at all complicated. If this be so, then to attribute to pathological forces the strength of the apparently healthy-minded and obviously effective 'behaver' would reduce psychological explanation to a string of paradoxes.

It has been urged, in conversation on this matter, as a reason why predictability cannot be taken as the differentia between sentiment and complex that under certain circumstances the conduct resulting from a complex may be predictable. If one leaves a claustrophobic patient alone in a strange cellar with the door shut but unlocked, it may be asserted that his behaviour can be successfully predicted. But before we can accept this statement certain considerations must not be forgotten. First, we are dealing here with a type of complex which involves only one emotional disposition, or at most very few. And the collocation of these dispositions does not organize the person's life as a whole, as love and hate tend to do. To borrow Mr Shand's phraseology from the preceding contribution, these dispositions inside the complex are "aggregates due to chance-associations"; not "organized forces in which the ideas and experiences are not merely associated with a common affect but relevant and subordinate to its end." Secondly, the fact that we are considering a phobia and not a fear is of importance. The patient's mind is not squarely filled by the impulse to rush from the room, but this phobic tendency is felt in its characteristic setting of doubt, hesitation and insufficiency, feeble though they may be if the impulse is intense. Given enough incentives he may postpone surrender to his weakness. But what are the most potent of such incentives? Surely, appeals to his well-established sentiments; to his regard for the good opinion of 
others and of himself; his courage or his love. Any of these, if they be strong, may compete successfully with the phobia.

But these incentives also have their behaviour counterparts in muscular and glandular changes, such as inhibition of movement or alteration in quality or amount of secretion. And since the 'incompleteness' of a phobia is one of its main characteristics, it may be concluded that the complete behaviour resulting from a complex is by no means predictable.

At this point, then, it may appear that after all, repression is the cause of the internal disorderliness in a collection of emotional dispositions relating to some object, and that the love or patriotism which have developed partly as a result of repression must be complexes, however reluctant people may be to acknowledge this state of affairs, This might be one way out of the difficulty, and it would have the merit of recognizing adequately the rôle of repression in sentiment-making. But there appear to be at least two cases which make this conception appear too simple. Mental growths possessing this characteristic of internal untidiness, and therefore unworthy of the name of sentiment, arise during the early stages of the formation of a sentiment, and during its decay or death. The 'love' for its parents of a child under six months of age can scarcely be termed a sentiment if that term is to be given the definition which we have accepted. For within the same five minutes such a child may display towards its parents the most startlingly varied emotions, some suggesting the presence of love, others of hate if we were to interpret them as signs of actual sentiments. But the inconstancy of such a young child's behaviour is its most striking feature, contrasting vividly with the regularity of its conduct when, a few years later, it has had time and opportunity to form real sentiments which come to its support in certain situations. At the other end of life, decay and disintegration may bring about in the sentiment a somewhat similar untidiness of internal organization when it once again becomes à complex.

Lastly, a complex, or a set of them, may result from the long-continued conflict of two sentiments, each of them strong and internally well-organized, but leading to incompatible lines of conduct. In a similar way two well-disciplined armies may fight until both are demoralized and lose their integrity.

Such a conception, I believe, reconciles several points of view. The oft-quoted examples of golf and photography appear as instances of sentiments in some persons; complexes in others. It seems to accord with medical, psychological and legal views of aberrations of behaviour. 
Lastly, it lends itself to interpretation along the lines of 'behaviourism' and of physiology. Theoretically, the emotional dispositions or tendencies in the definition must be capable of translation into terms of their physiological concomitants. The functional inter-relation of their neural controlling mechanisms may be complex or simple, 'tidy' or 'untidy.' The dominant pattern of the sentiment may be like a well-arranged switch-board, that of the complex like an untidy bunch of live wires. From the latter we may expect many more short-circuits and perhaps, breakdown of insulation; but this is a line of thought which cannot be pursued in this paper.

In this view, psycho-analysis would be a sorting out and disentangling of the emotional tendencies in the complex, a 'straightening,' to borrow Samuel Butler's term. Re-education, whether deliberately carried out or arising incidentally during the treatment, would be the attachment of the liberated energy to other worthier objects, and the formation of more effective sentiments about the original objects. And if this be correct we can understand how mere analysis, without re-education, may leave a patient with no ethical or other values potent enough to lead him successfully through life.

In conclusion, perhaps I may be pardoned if I introduce an analogy which may make some of these points clearer to the untechnical reader. If we consider the fact that a single object in the environment does not usually produce in the average man one single pure emotion, but rather a blend of two or more emotions, the likeness of his experience to the chord in music is naturally suggested. May we compare the sentiment to an organization of potentialities for producing blends of musical notes?

Such an organization exists in the moving roll of paper which actuates the notes of an automatic piano player. Whenever a hole in the paper passes a corresponding hole in a brass cylinder, a note is played. The pitch of this note depends upon its horizontal position on the moving roll; its intensity upon the size and its duration upon the length of the hole. Blends of notes occur when holes in the same horizontal line pass across the cylinder.

We may compare the roll to the material substratum, the physiological basis of the sentiment. The notes heard may be likened to the emotions which are actually experienced. Just as on Prof. McDougall's theory, the term sentiment stands for something which itself is never experienced but is part of the structure of the mind ${ }^{1}$, so the roll, though

1 Mr Shand's definition of a sentiment includes the phrase "a system of several emotional dispositions...." 
it is never heard, is the material bearer of the organization of the notes. And if the reader objects-as he ought to-that the roll is dead while the physiological basis of the sentiment is living, let us suppose that, a few years hence, musicians will record their compositions directly on the paper roll and that it will therefore be usual for a composer to alter the pattern of holes every day during the growth of his composition; widening and narrowing some holes, lengthening and shortening others, and occasionally adding new or obliterating old ones.

We know that, mathematically regarded, the number of possible combinations of notes which can be played simultaneously on such an instrument is infinite: we know, too, that the number which is actually played in practice, though huge, is much smaller than infinity and that the laws of fusion and consonance explain why this is so. So it is probably with the sentiment, for the emotions may have their own laws of fusion and consonance. We know again that a person accustomed only to the simpler musical intervals and chords may declare that our modern music is but a collection of noises; we know too that its composers can often demonstrate quite convincingly that their use of certain 'new' intervals is but an extension of laws already known. Does not a similar situation exist in regard to some of our modern sentiments? Do not old-fashioned people complain bitterly and sometimes justly, of the untidiness of sentiments in the twentieth century as compared with the tidiness of those in the nineteenth? May not the explanation be that they, in the famous phrase, have a bad ear for new music?

And so our analogy brings us again to the question of predictability; by and for whom? The answer is simpler in the realm of music. Though to the listener who is only accustomed to the simpler chords and sequences the modern compositions are unpredictable, the student who has analysed them finds that much of their mystery vanishes. So it may be with the psycho-therapist or the priest who himself brought up in a tidier world is trying to understand minds which have developed in the tangle of the last ten years. He often finds it difficult to decide whether the emotional dispositions of such personalities are organized in sentiments or complexes-and no wonder. Yet he can learn something from the attitude of musical critics throughout the ages.

And this analogy is only strengthened by the fact that in spite of this tolerant attitude towards new music everyone recognises that there do exist cacophonies which cannot possibly be fitted into any known laws of consonance. This complete lack of organization of emotional tendencies would characterize the extreme instance of the complex.

J. of Psych. xrII. 2 
It may be not without interest to continue this analogy a little further. On hearing a few bars played by an instrument such as that which has been described, an expert, judging merely by the particular blends and successions of notes may often identify the music as definitely characteristic of a certain composer, a certain school, or a certain period. So we can sometimes confidently speak of certain sentiments and integrations of sentiments as characteristic of certain persons, perhaps indeed of certain nationalities at certain times. Along the lines of such an analogy, the integration of sentiments is not difficult to conceive; nor is the disintegration of a sentiment into a complex as a result of the continued introduction of intense emotions of a quality foreign to those already represented in it. And lastly, if we suppose the holes in the roll to be blocked up, added to or enlarged through the action of damp or mould, we can imagine the process by which, under the influence of bodily disease, a sentiment may decay. 